Mạnh Hùng (2010), "Nghiên cứu mô hình bệnh tât ở bệnh nhân điêuu trị nôi trú tai Viên Tim mạch Việt nam trong thời gian 2003-2007". Tạp chí Tim mạch học Việt Nam, số 52, tr. 11-17.

2. Goode SD, Cleveland TJ, Gaines (2013). "Randomized clinical trial of stents versus angioplasty for the treatment of iliac artery occlusions (STAG trial)". British Journal of Surgery; 100(9): pp.1148-53.

3. Kudo T, Chandra FA, Ahn SS (2005) "Long-term outcomes and predictors of iliac angioplasty with selective stenting", J Vasc Surg, 42(3): pp.466-75.

4. Taylor M Spence, John W. York (2010), "Lower Extremity Arterial Disease: Decision Making and Medical Treatment", Rutherford's Vascular Surgery, 7 ed., 2, Chap 104, pp.1593 - 1612.

5. Timaran, et al (2001), "External iliac and common iliac artery angioplasty and stenting in men and women", J Vasc Surg; Vol 34(3), pp.440-446.

6. Van Haren R.M., et al (2017), "Endovascular treatment of TransAtlantic Inter- Society Consensus $D$ aortoiliac occlusive disease using unibody bifur- cated endografts", ] Vasc Surg, 65(2): p. 398-405.

7. Rutherford RB, Baker JD, Ernst C, Johnston KW, Porter JM, Ahn S, Jones DN (1997) "Recommended standards for reports dealing with lower extremity ischemia: revised version". J Vasc Surg, 26, pp.517-538.

8. Pulli $R$, Dorigo $W$, Fargion $A$, Innocenti AA, Pratesi G, Marek J, Pratesi C (2011), "Early and long-term comparison of endovascular treatment of iliac artery occlusions and stenosis". J Vasc Surg, 53(1), pp.92-98.

\title{
MộT SỐ YẾU TỐ LIÊN QUAN ĐẾN MÂT Độ XƯƠ'NG Ở NGƯỜI BỆNH CAO TUỔI TẠI BỆNH VIÊ̂N LÃO KHOA TRUNG ƯƠNG
}

\section{TÓM TẮT}

Nghiên cứu cắt ngang mục tiêu phân tích một số yếu tố liên quan đến mật độ xương ở người cao tuổi điều trị tại bệnh viện Lão Khoa Trung Ương. 300 người bệnh đến khám tại khoa khám bệnh, khoa khám bệnh theo yêu cầu và điều trị nôi trú tại khoa nội tiết và cơ xương khớp Bệnh viện Lã̃o Khoa Trung Ương thỏa mãn các điều kiên (i) Tuổi $\geq 60$, (ii) Đồng ý tham gia nghiên cứu. Loại ra khỏi nghiên cứu các đối tượng (i) Đái tháo đường, (ii) Loãng xương thứ phát, (iii) Đã điều trị loãng xương. Kết quả cho thấy Phần lớn loãng xương găp ở nhóm tuổi $\geq 80$. Tuổi trung bình của nhóm loã̉ng xương là $73,3 \pm 7,6$. Chủ yếu găp ở nư giới (93,6\%). Mật độ xương giảm dân theo tuổi ở cả 2 vị trí $C S T L$ và $C X \bigoplus(p<0,05)$. Khả năng người bệnh tập thể dục không có loãng xương cao gấp 1,8 lần người không tập thể dục $(95 \% \mathrm{CI}: 1,3-2,4)$. Nguy cơ người có bệnh lý nền xuất hiện tình trạng loãng xương cao gấp 2,37 lần những người không có bệnh lý nền (95\%CI: 1,8 - 3,1). Mật độ xương ở cột sống thắt lưng và mât đô xương ở cổ xương đùi có mối tương quan nghịch với Cholesterol TP, Triglycerid và $\mathrm{HDL}-\mathrm{C}$ $(p<0,01)$. Ngược lai, mật độ xương ở côt sống thắt lưng và mật độ xương ở cổ xương đùi có mối tương quan thuân với $L D L-C$.

Tư khoá: mật độ xương; người già;

\section{SUMMARY}

*Bênh viện Lão Khoa Trung Uơng

**Bênh viện Bach Mai

***Đai hoc Y Hà Nôi

Chịu trách nhiệm chính: Hoàng Thị Bích

Email: mimosahoangbich@gmail.com

Ngày nhận bài: 12.7.2021

Ngày phản biên khoa hoc: 8.9.2021

Ngày duyệt bài: 14.9.2021

\section{SOME FACTORS RELATED TO BONE DENSITY IN GERIATRIC PATIENTS AT THE NATIONAL GERIATRIC HOSPITAL}

A cross-sectional study aimed at analyzing some factors related to bone density in elderly people treated at the National Geriatric Hospital. 300 patients visited the medical examination department, ondemand examination department and inpatient treatment at the Department of Endocrinology and Musculoskeletal system at the National Geriatric Hospital satisfying the following conditions (i) Age $\geq$ 60, (ii) Agree to participate in the study. Excluded from the study subjects (i) Diabetes, (ii) Secondary osteoporosis, (iii) Treated osteoporosis. The results show that the majority of osteoporosis occurs in the age group $\geq 80$. The mean age of the osteoporosis group is $73.3 \pm 7.6$. Mainly seen in women (93.6\%). Bone density decreased with age in both lumbar spine and vertebral column $(p<0.05)$. Patients who exercise without osteoporosis are 1.8 times more likely than those who do not exercise (95\% CI: $1.3-2.4$ ). The risk of people with underlying medical conditions developing osteoporosis is 2.37 times higher than those without underlying disease (95\% CI: $1.8-3.1$ ). Bone density in lumbar spine and bone density in femoral neck were negatively correlated with cholesterol TP, Triglyceride and HDL - C $(p<0.01)$. In contrast, bone density in the lumbar spine and bone density in the femoral neck were positively correlated with LDL-C.

Keywords; osteoporosis density; old person;

\section{I. ĐĂT VẤN ĐỀ}

Loãng xương là bệnh lý ảnh hưởng đến toàn bộ hệ thống xương, giảm sức mạnh của xương, gia tăng nguy cơ gãy xương ảnh hưởng lớn tới chất lượng cuộc sống có thể gây tử vong ở người 
có tuổi song lại không có biểu hiện lâm sàng. Hiện nay có hơn 200 triệu người trên thế giới mắc loãng xương nhưng chỉ 10- $20 \%$ được chẩn đoán và điều trị. Cứ mổi 3 giây lại có một người gãy xương do loãng xương, hàng năm có tới 8,9 triệu case gãy xương do loãng xương gây ảnh hưởng lớn tới chất lượng cuộc sống có thể gây tử vong ở người có tuổi ${ }^{1}$. Tại Mỹ chi phí điều trị loãng xương ước tính lên tới 25,3 tỷ $\$$ vào năm 2025, tổng chi phí điều trị gãy xương do loãng xương lên tới 81000 \$/người trong suốt phần đời còn laii².

Loãng xương không chỉ xuất hiện một mình, đi kèm với nó là các bệnh tim mạch như đột quy, nhồi máu cơ tim đưa tới gánh nặng bệnh tật rất lớn, nguy cơ tử vong rất cao. Việc phát hiện sớm các nguy cơ dẫn đến đột quy, nhồi máu cơ tim trên bệnh nhân loãng xương là hết sức cần thiết. Đo bề dày lớp nội trung mạc động mạch cảnh không những giúp phát hiện sớm xơ vữa động mạch cảnh mà còn giúp dự báo sớm nguy cơ xơ vữa các động mạch khác cũng như nguy cơ loãng xương, từ đó có biện pháp điều trị và dự phòng phù hợp tránh các nguy cơ đáng tiếc có thể xảy ra, đặc biệt là tử vong. Nhiều nghiên cứu nước ngoài thấy có mối tương quan thuận giữa mật độ xương thấp và tăng bề dây lớp nội trung mạc động mạch cảnh ở cả hai giới ${ }^{2}$.

Ở Việt Nam đã có nghiên cứu về mối liên quan giữa mật độ xương và bề dày lớp nội trung mạc động mạch cảnh bước đầu đã thấy mối tương quan giữa mật độ xương vùng cổ xương đùi với bề dày lớp nội trung mạc động mạch cảnh ở nam giới trên 50 tuổi ${ }^{3}$. Do đó, chúng tôi tiến hành nghiên cứu đề tài "Một số yếu tố liên quan đến mật độ xương ở người bệnh cao tuổi tại bệnh viện Lão Khoa Trung Ương" với mục tiêu. "Phân tích một số yếu tố liên quan đến mật độ xương ở người cao tuổi đến khám và điều trị tại bệnh viện Lão Khoa Trung Uơng"

\section{II. ĐỐI TƯợNG VÀ PHƯƠNG PHÁP NGHIÊN CỨU}

2.1. Đối tượng nghiên cứu: Người bệnh đến khám tại khoa khám bệnh, khoa khám bệnh theo yêu cầu và điều trị nội trú tại khoa nội tiết và cơ xương khớp Bệnh viện Lão Khoa Trung Ương thỏa mãn các điều kiện (i) Tuổi $\geq 60$, (ii) Đồng ý tham gia nghiên cứu. Loại ra khỏi nghiên cứu các đối tượng (i) Đái tháo đường, (ii) Loãng xương thứ phát, (iii) Đã điều trị loãng xương

\subsection{Thời gian và địa điểm nghiên cứu}

2.2.1. Thời gian nghiên cứu: từ tháng $8 / 2020$ đến tháng $8 / 2021$.

2.2.2. Địa điểm nghiên cứu: Khoa khám bênh, khoa khám bệnh theo yêu cầu, khoa nội tiết và cơ xương khớp Bệnh Viện Lão Khoa TW.

\subsection{Phương pháp nghiên cứu}

2.3.1. Thiết kế nghiên cứu: Nghiên cứu mô tả cắt ngang

2.3.2. Cỡ mẫu và cách chọn mẫu: Nghiên cứu sử dụng cách chọn mẫu thuận tiện. Lựa chọn tuần tự người bệnh đến khám khám bệnh, khoa khám bệnh theo yêu cầu và điều trị nội trú tại khoa nội tiết và cơ xương khớp Bệnh viện Lão Khoa Trung Ương đảm bảo tiêu chuẩn lựa chọn và tiêu chuẩn loại trừ. Kết thúc nghiên cứu chúng tôi thu đước 300 người bệnh. Trong đó có 156 người bệnh loãng xương và 144 người bệnh không loãng xương.

2.4. Biến số nghiên cứu: Tuổi, giới, mật độ xương, cholesterol TP, triglycerid, HDLC, LDLC, hút thuốc lá, lạm dụng rượu, bia, tập thể dục.

2.5. Công cụ đánh giá và thu thập số liệu: Bệnh án chuyên biệt dành riêng cho nghiên cứu.

2.6. Phân tích số liệu: Sau khi mã hóa thông tin, nghiên cứu viên trực tiếp nhập liệu bằng phần mềm SPSS 20.0 và làm sạch số liệu trước khi phân tích. Các biến định tính được thổng kê mô tả với tần số và phần trăm. Các biến định lượng được thống kê mô tả với trung bình, độ lệch chuẩn, giá trị nhỏ nhất và giá trị lớn nhất. Sử dụng kiểm định khi bình phương, Fisher exact test, T-Test. Có ý nghĩa thống kê khi $p<0,05$.

2.7. Đạo đức nghiên cứu: Đây là nghiên cứu mô tả lâm sàng, không can thiệp vào các phương pháp điều trị của bác sĩ. Nghiên cứu được tiến hành khi có sự đồng ý của hội đồng chuyên khoa cấp II của Bộ môn Lão Khoa Trường Đại học Y Hà Nội và của hội động Y Đức Trường Đại học Y Hà Nội.

\section{KẾT QUẢ NGHIÊN CỨU}

Bảng 3.1: Đặc điểm về tuổi của nhóm nghiên cứu $(n=300)$

\begin{tabular}{|c|c|c|c|c|c|c|c|}
\hline \multirow{2}{*}{$\begin{array}{cc}\text { Tình trăng } \\
\text { Nhóm tuổi }\end{array}$} & \multicolumn{2}{|c|}{ Loãng xương } & \multicolumn{2}{|c|}{$\begin{array}{c}\text { Không loãng } \\
\text { xương }\end{array}$} & \multicolumn{2}{|c|}{ Chung } & \multirow{2}{*}{$\mathbf{p}$} \\
\hline & $\mathbf{n}$ & $\%$ & $\mathbf{n}$ & $\%$ & $\mathbf{n}$ & $\%$ & \\
\hline $60-69$ tuô̂i & 50 & 43,1 & 66 & 56,9 & 116 & 100,0 & \multirow{3}{*}{0,04} \\
\hline $70-79$ tuối & 67 & 57,3 & 50 & 42,7 & 117 & 100,0 & \\
\hline$\geq 80$ tuối & 39 & 58,2 & 28 & 41,8 & 67 & 100,0 & \\
\hline Tống & 156 & 52,0 & 144 & 48,0 & 300 & 100,0 & \\
\hline
\end{tabular}


Tuối trung bình

$73,3 \pm 7,6$

$70,9 \pm 7,6$

$72,1 \pm 7,7 \quad 0,011$

Nhận xét: Phần lớn loãng xương gặp ở 2 nhóm tuối $70-79$ và nhóm tuối $\geq 80$ hơn là không loãng xương, sự khác biệt có ý nghĩa thống kê với $p=0,04$. Tuổi trung bình của nhóm loãng xương là $73,3 \pm 7,6$ cao hơn nhóm không loãng xương $(70,9 \pm 7,6)$, sự khác biệt có ý nghĩa thống kê với $p$ $=0,011$.

Bảng 3.2. Mật độ xương trung binh theo tuổi

\begin{tabular}{|c|c|c|c|c|}
\hline BMD Nhóm tuổi & $\mathbf{6 0}-\mathbf{6 9}$ & $\mathbf{7 9}-\mathbf{7 9}$ & $\mathbf{2 8 0}$ & $\mathbf{p}$ \\
\hline CSTL & $0,772 \pm 0,165$ & $0,733 \pm 0,144$ & $0,707 \pm 0,167$ & 0,02 \\
\hline CX甲 & $0,743 \pm 0,180$ & $0,705 \pm 0,163$ & $0,676 \pm 0,155$ & 0,01 \\
\hline
\end{tabular}

Nhân xét: Mật độ xương trung bình giảm dần theo tuối ở cả 2 vị trí CSTL và CXĐ có ý nghĩa thống kê $(p<0,05)$

Bảng 3.3. Môi liên quan giữa tập thể dục, hút thuốc lá và uống rượu bia với tình trạng loãng xương

\begin{tabular}{|c|c|c|c|c|c|c|c|}
\hline \multirow{2}{*}{\multicolumn{2}{|c|}{$\begin{array}{lr}\text { Tình trạng } \\
\text { Noóm tuổi }\end{array}$}} & \multicolumn{2}{|c|}{ Loãng xương } & \multicolumn{2}{|c|}{$\begin{array}{l}\text { Không loãng } \\
\text { xương }\end{array}$} & \multirow{2}{*}{$95 \% \mathrm{CI}$} & \multirow{2}{*}{$\mathbf{p}$} \\
\hline & & $\mathbf{n}$ & $\%$ & $\mathrm{n}$ & $\%$ & & \\
\hline \multirow{2}{*}{ Tập thể dục } & Có & 2 & 18,2 & 9 & 81,8 & \multirow{2}{*}{$\begin{array}{c}1,8 \\
(1,3-2,4)\end{array}$} & \multirow{2}{*}{0,022} \\
\hline & Không & 154 & 53,3 & 135 & 46,7 & & \\
\hline \multirow{2}{*}{ Uống rượu bia } & Có & 4 & 44,4 & 5 & 55,6 & \multirow{2}{*}{$\begin{array}{c}0,8 \\
(0,4-1,8)\end{array}$} & \multirow{2}{*}{$0,7^{*}$} \\
\hline & Không & 152 & 52,2 & 139 & 47,8 & & \\
\hline \multirow{2}{*}{ Bệnh lý nền } & Có & 109 & 71,2 & 44 & 28,8 & \multirow{2}{*}{$\begin{array}{c}2,37 \\
(1,8-3,1)\end{array}$} & \multirow{2}{*}{$<0,01$} \\
\hline & Không & 47 & 32,0 & 100 & 28,8 & & \\
\hline
\end{tabular}

*Fisher's Exact Test

Nhận xét: Phần lớn người bệnh tập thể dục không có biểu hiện loãng xương, sự khác biệt có ý nghĩa thống kê với $p=0,022$. Khả năng người bệnh tập thể dục không có loãng xương cao gấp 1,8 lần người không tâp thể dục ( $95 \% \mathrm{CI}: 1,3-$ 2,4). Những người bệnh có bệnh lý nên có tỉ lệ loãng xương cao hởn những người không có bệnh lý nền, sự khác biệt có ý nghĩa thống kê với $p<0,01$. Nguy cơ người có bệnh lý nền xuất hiện tình trạng loãng xương cao gấp 2,37 lần những người không có bệnh lý nền (95\%CI: 1,8 - 3,1).

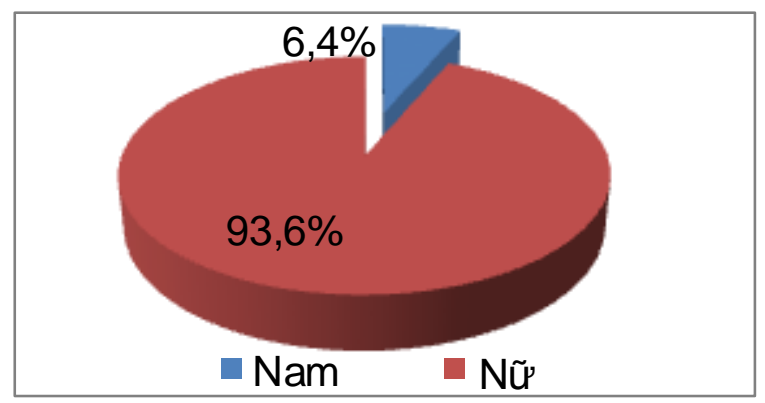

Biểu đồ 3.1: Phân bố loãng xương theo giới $(n=156)$

Nhân xét: Hầu hết loãng xương gặp ở nữ giới với tỉ lệ 93,6\%. Sự khác biệt giữa hai giới có ý nghĩa thống kê với $\mathrm{p}<0,01$. Tỉ lệ nữ : nam xấp xỉ $15: 1$.

Bảng 3.4. Tương quan giữa giữa mật độ xương ớ CSTL, CXD với Cholesterol TP,
Triglycerid, $H D L, L D L$

\begin{tabular}{|c|c|c|c|c|}
\hline \multirow{2}{*}{ Biến số } & \multicolumn{2}{|c|}{$\begin{array}{l}\text { Mật độ xương } \\
\text { CSTL }\end{array}$} & \multicolumn{2}{|c|}{$\begin{array}{l}\text { Mật độ xương } \\
\text { CXD }\end{array}$} \\
\hline & $\mathbf{r}$ & $\mathbf{p}$ & $\mathbf{r}$ & $\mathbf{p}$ \\
\hline Cholesterol TP & $-0,24$ & $<0,01$ & $-0,19$ & 0,001 \\
\hline Triglycerid & $-0,21$ & $<0,01$ & $-0,16$ & 0,005 \\
\hline $\mathrm{HDL}-\mathrm{C}$ & $-0,35$ & $<0,01$ & $-0,31$ & $<0,01$ \\
\hline $\mathrm{LDL}-\mathrm{C}$ & 0,09 & 0,1 & 0,22 & $<0,01$ \\
\hline
\end{tabular}

Nhân xét: Mật độ xương ở cột sông thắt lưng và mật độ xương ở cổ xương đùi có mối tương quan nghịch với Cholesterol TP, Triglycerid và $\mathrm{HDL}-\mathrm{C}$, có ý nghĩa thống kê với $\mathrm{p}<0,01$. Ngược lại, mật độ xương ở cột sống thắt lưng và mật độ xương ở cổ xương đùi có mối tương quan thuận với LDL - C. Tuy nhiên tương quan giữa mật độ xương cột sống thắt lưng và $L D L-C$ không có ý nghĩa thống kê $(p>0,05)$.

\section{BÀN LUÂ̂N}

Nghiên cứu của chúng tôi tập trung vào người cao tuổi nên chọn mẫu là 300 người từ 60 đến 90 tuổi. Chúng tôi nhận thấy phần lớn loãng xương gặp ở 2 nhóm tuổi $70-79$ và nhóm tuổi $\geq 80$ hơn là không loãng xương, sự khác biệt có ý nghĩa thống kê với $p=0,04$. Tuổi trung bình của nhóm loãng xương là $73,3 \pm 7,6$ cao hơn nhóm không loãng xương $(70,9 \pm 7,6)$, sự khác biệt có ý nghĩa thống kê với $\mathrm{p}=0,011$ (bảng 3.1). Tương tự như kết quả nghiên cứu của MK Garg và cộng sự (2017) khi nghiên cứu trên 
2347 người cao tuổi tại Ấn Độ4. Trong nghiên cứu của chúng tôi, số bệnh nhân loãng xương tham gia nghiên cứu là 156 người, bệnh nhân không loãng xương là 144 người. Hầu hết loãng xương gặp ở nữ giới với tỉ lệ 93,6\%. Sự khác biệt giữa hai giới có ý nghĩa thống kê với $p<0,01$. Tỉ lệ nữ : nam xấp xỉ $15: 1$ (biểu 1).

Kết quả nghiên cứu bảng 3.2 cho thấy tuổi nhóm tuổi 60 - 69 có mật độ xương ở cột sống thắt lưng là $0,772 \pm 0,165$ cao hơn nhóm $79-$ 79. Và nhóm tuổi 79 - 79 có mật độ xương ở cột sống thắt lưng cao hơn nhóm tuổi từ 80 trở lên, $0,733 \pm 0,144$ so với $0,707 \pm 0,167$. Sự khác biệt giữa các nhóm tuổi có ý nghĩa thống kê với $\mathrm{p}=0,02$. Đồng thời, mật độ xương ở cổ xương đùi nhóm tuổi $60-69$ là $0,743 \pm 0,180$ cao hơn nhóm tuổi $70-79$. Nhóm tuổi 70 - 79 có mật độ xương ở cổ xương đùi cao hơn nhóm tuổi từ 80 trở lên, $0,705 \pm 0,163$ so với $0,676 \pm 0,155$, sự khác biêt có ý nghĩa thống kê với $p=0,01$. Từ kết quả này có thể thấy mật độ xương ở vị trí cột sống thắt lưng và vị trí cổ xương đùi có xu hướng giảm dần khi tuổi càng tăng.

Cholesterol được vận chuyển bởi 2 loại là lipoprotein là LDL và HDL. LDL cholesterol (yếu tố tấn công) và HDL cholesterol (yếu tố bảo vệ). Ở người cao tuổi sự sụt giảm hormon sinh dục (estrogen ở nữ và androgen ở nam) làm tăng LDL cholesterol, giảm HDL cholesterol. Cộng với lối sống tĩnh tại, ít vận động thể dục thể thao càng làm tăng LDL cholesterol. Sự tích tụ LDL cholesterol và các sản phẩm oxy hóa của nó trong các mạch xương và nội mô xương sẽ ức chế tạo cốt bào tăng hoạt động của hủy cốt bào, hướng các tế bào cơ bản của xương biệt hóa thành tế bào mõ, giảm Alkaline phosphatase và Osteocalcin trong xương dẫn đến mất xương.

Theo bảng 3.4 có mối tương quan nghịch giữa cholesterol toàn phần và mật độ xương ở cả 2 vị trí cột sống thắt lưng và cổ xương đùi $(r=-$ 0,24 và $-0,190 ; p<0,01$ ). Các tác giả trong và ngoài nước cũng thây mối tương quan nghịch giữa cholesterol toàn phần và mật độ xương ${ }^{4}$. Daniel $H$ và cộng sự khi nghiên cứu trên 13522 người Mỹ thấy có mối liên quan giữa tăng nồng độ cholesterol và mật độ xương thấp ( $\mathrm{p}<$ $0,001)$. MK Garg nghiển cứu trên 2347 người Ấn Độ (39,4\% nam, 60,6\% nữ) thấy mối tương quan giữa tăng cholesterol toàn phần và giảm BMD cổ xương đùi, BMD cột sống thắt lưng ở nam giới $(p<0,0001$ và 0,004$)$; giảm tổng $B M D$ cổ xương đùi ở phụ nữ sau mãn kinh $(p=$ 0,024). S.Adami nghiên cứu trên đối tượng 6875 tuổi thãy mối tương quan chặt chẽ giữa BMD
CSTL và $\mathrm{CX \boxplus} \mathrm{với} \mathrm{cholesterol} \mathrm{toàn} \mathrm{phần.} \mathrm{Có} \mathrm{mối}$ tương quan nghịch giữa triglycerid và mật độ xương ở cả 2 vị trí CSTL và $C X \bigoplus(r=-0,21$; và 0,$16 ; p<0,001$ ) (bảng 3.4). Triglyceride là thành phần chủ yếu của các lipoprotein trọng lượng phân tử rất thấp (VLDL). VLDL có thể chuyển hoá thành LDL. Sự tích tụ của LDL và các sản phẩm oxy hóa của chúng trong mạch xương và nội mô xương ức chế tạo cốt bào, tăng hủy cốt bào dẫn đến mất xương. Ở người cao tuổi, sự sụt giảm hormon sinh dục làm tăng nồng độ triglycerid đưa đến mất xương nhanh. Lối sống tĩnh tại, ít vận động cũng làm tăng mất xương. Có hiện tượng này là do sự vận động của các cơ kích thích sự tạo xương và tăng khối lượng xương, ngược lại sự giảm vận động dẫn đến mất xương nhanh. Tuy nhiên tập luyện quá mức lại có tác dụng ngược lại. Theo Wiliam C và cộng sự chạy marathon ở phụ nữ trẻ dẫn đến giảm cân và mất mát của chu kỳ kinh nguyệt có thể thúc đẩy quá trình mất xương ${ }^{5}$. Nevillie và cộng sự nghiên cứu ảnh hưởng của mức độ tập luyện với mật độ xương của 242 nam và 212 nữ tuổi $20 \div$ 25 ở Irelan đã đưa ra kết luận: tập luyện thể thao với cường độ lớn và kéo dài gây căng thẳng cho những người trẻ tuổi và có thể làm giảm khối lượng xương đỉnh của họ. Như vậy tập thể dục - thể thao có vai trò rất quan trọng với mật độ xương nhưng tập luyện như thế nào để đạt hiệu quả cao nhất mới là vấn đề cần quan tâm. LDLc được biết đến như một loại cholesterol xấu, không chỉ làm tăng xơ vữa mạch máu mà còn gây mất xương nghiêm trọng. Lipid đã được chứng minh là tích tụ trong xương của chuột và xung quanh mạch xương ở những bệnh nhẩn bị loãng xương. Các sản phẩm oxy hóa của LDL ức chế hoạt động của hủy cốt bào, hướng tiền tạo cốt bào biệt hóa thành tế bào mõ̃, tăng hoạt động của hủy cốt bào dẫn đến mất xương nhanh chóng đặc biệt trên người cao tuổi sự sụt giảm estrogen và androgen làm tăng LDL càng thúc đẩy nhanh quá trình mất xương. Có mối tương quan nghịch giữa $\mathrm{HDL}$ - $\mathrm{C}$ và mật độ xương ở cả 2 vị trí $C S T L$ và $C X \oplus(r=-0,35$ và $-0,31 ; p<$ 0,001 ) (bảng 3.4). Kết quả nghiên cứu của chúng tôi tương tự như kêt quả nghiên cứu của các tác giả nước ngoài. MK Garg nghiên cứu trên người Ân Độ thấy mối tương quan giữa tăng LDLC và giảm $B M D$ cổ xương đùi, cột sống thắt lưng ở nam giới $(p=0,001$ và 0,01$)$ và phụ nữ tiên mãn kinh $(p=0,007)$; tương quan giữa giảm tổng BMD cổ xương đùi và tăng LDLc ở phụ nữ mãn kinh. S.Adami nghiên cứu trên 265 nam, 481 nữ 68 - 75 tuổi thấy mối tương quan chặt 
chẽ giữa $B M D$ cột sống thắt lưng và cổ xương đùi với LDLC. Có mối tương quan đồng biến giữa $L D L-C$ và mật độ xương ở cả 2 vị trí CSTL và CXĐ. Ở mật độ xương CSTL có hê số tương quan $r=0,09$. Tuy nghiên sự khác biệt không có ý nghĩa thống kê với $p=0,1$. Còn ở mật độ xương CX甲 có hệ số tương quan là $r=0,22$, sự khác biệt có ý nghĩa thống kê với $p<0,001$ (bảng 3.4). Kết quả này tương tự như kết quả nghiên cứu của MK Garg, S.Adami.

\section{KẾT LUẬN}

Phần lớn loãng xương gặp ở nhóm tuổi $\geq 80$. Tuổi trung bình của nhóm loãng xương là $73,3 \pm$ 7,6 . Chủ yếu gặp ở nữ giới $(93,6 \%)$. Mật độ xương giảm dần theo tuổi ở cả 2 vị trí CSTL và CXĐ $(p<0,05)$. Khả năng người bệnh tập thể dục không có loãng xương cao gấp 1,8 lần người không tập thể dục $(95 \% \mathrm{CI}: 1,3-2,4)$. Nguy cơ người có bệnh lý nền xuất hiện tình trạng loãng xương cao gấp 2,37 lần những người không có bệnh lý nền (95\%CI: 1,8-3,1). Mật độ xương ở cột sống thắt lưng và mật độ xương ở cổ xương đùi có mối tương quan nghịch với Cholesterol TP, Triglycerid và $\mathrm{HDL}-\mathrm{C}(\mathrm{p}<0,01)$. Ngược lại, mật độ xương ở cột sống thắt lưng và mật độ xương ở cổ xương đùi có mối tương quan thuận với $\mathrm{LDL}-\mathrm{C}$.

Lời cảm ơn: Chúng tôi xin chân thành cám ơn những người bệnh Khoa khám bệnh, khoa khám bênh theo yểu cầu, khoa nôi tiết và cơ xương khớp Bệnh Viện Lão Khoa Trung Ương và Bộ môn Nội Tổng Hợp, Bộ môn Lão Khoa, Trường Đại học Y Hà Nội đã tạo điều kiện đế thực hiện nghiên cứu.

\section{TÀI LIỆU THAM KHẢO}

1. https://www.news-medical.net/health/BoneDisease.aspx. Last Updated: Oct 31, 2017.

2. Bone Disease. News-Medical.net. Published August 12, 2009. Accessed September 22, 2021. https://www.news-medical.net/health/Bone-

Disease.aspx

3. Garg MK, Marwaha RK, Tandon N, Bhadra K, Mahalle $\mathbf{N}$. Relationship of lipid parameters with bone mineral density in Indian population. Indian J Endocrinol Metab. 2014;18(3):325-332. doi:10.4103/2230-8210.131165

4. Kim T, Park S, Pak Y-S, Lee S, Lee E-H. Association between metabolic syndrome and bone mineral density in Korea: the Fourth Korea National Health and Nutrition Examination Survey (KNHANES IV), 2008. ] Bone Miner Metab. 2013; 31(6):652-662. doi:10.1007/s00774-013-0459-4

5. William C. Shiel Jr, M., FACP, FACR. Osteoporosis Treatment, Medication, symptoms, prevention... MedicineNet on health.com. Published online 2012.

\section{ĐÁNH GIÁ BƯớC ĐẦU KÊTT QUẢ NUÔI CẤY PHÔI BẰNG MÔI TRƯờNG ĐƠN BƯỚC CSC TẠI BÊ̂NH VIỆN ĐẠI HỌC Y HÀ NộI}

\section{Tạ Thị Quỳnh Giao', Bùi Thanh Thủy ${ }^{1}$, Nguyễn Khang Sơn ${ }^{2}$}

\section{TÓM TẮT}

Mục tiêu: Đánh giá bước đâu kết quả nuôi cấy phôi bằng môi trường đơn bước CSC và xác định một số yếu tố liên quan. Đối tượng và phương pháp nghiên cứu: Nghiên cứu quan sát, mô tả theo dõi dọc trên 66 phụ nữ làm thụ tinh trong ống nghiệm với 806 noãn MII được ICSI tại Trung tâm Hố trợ sinh sản, Bệnh viện Đại học Y Hà Nội, từ tháng 1/2021 đến tháng $8 / 2021$. Trong đó có 479 noãn sau ICSI được theo dõi nuôi cấy liên tục đến ngày 5 bằng môi trường đơn bước CSC có thay mới môi trường vào ngày 3 . Các biến nghiên cứu chính là tỷ lệ thụ tinh, chất lượng phôi giai đoạn phân cắt (ngày 2), chất lượng phối nang và một số yếu tố liên quan. Kết quả: Tỷ lệ thụ

\footnotetext{
${ }^{1}$ Trường Đại học Y Dược Thái Nguyên ${ }^{2}$ Trường Đai hoc Y Hà Nôi

Chịu trách nhiệm chính: Nguyễn Khang Sơn

Email: khangson@gmail.com

Ngày nhận bài: 19.7.2021

Ngày phản biên khoa hoc: 6.9.2021

Ngày duyệt bài: 20.9.2021
}

tinh đạt $91,66 \pm 12,92 \%$, tỷ lệ tạo phôi ngày 2 là $98,34 \pm 5,40 \%$, tỳ lệ tạo phôi nang là 73,07 \pm $13,06 \% \%$, tỷ lệ phôi nang hữu dụng đạt $69,81 \pm$ $12,96 \%$. Chất lượng noãn và tinh trùng tại thời điểm ICSI ảnh hưởng đến tỷ lệ thụ tinh, tỷ lệ phôi nang hữu dụng, sự khác biệt có ý nghĩa thống kê $(p<0,05)$.

Tư khóa: Phôi giai đoạn phân cắt, phôi nang hữu dụng, nuôi cấy phôi, môi trường đơn bước, môi trường chuyển tiếp.

\section{SUMMARY \\ RESULTS OF EMBRYO CULTURE BY CSC SINGLE-STEP CULTURE MEDIUM AT HANOI} MEDICAL UNIVERSITY HOSPITAL

Objectives: The study aims to initially evaluate the results of embryo culture using CSC single-step medium and compare with the results of embryo culture in transition medium. Subject and method: A prospective study was conducted on 66 women having IVF with 806 MII oocytes obtained by ICSI at the IVF Center, Hanoi Medical University Hospital, from August 2020 to August 2021. In which, 479 oocytes after ICSI were cultured continuously until day 